\title{
HUBUNGAN TINGKAT PENGETAHUAN DAN SIKAP IBU TERHADAP PERILAKU PENGGUNAAN KONTRASESPSI KB DI PUSKESMAS SIKO KECAMATAN KOTA TERNATE UTARA TAHUN 2013
}

\author{
Hetty Astri*), Farida Alhadar ${ }^{*}$
}

\begin{abstract}
The high rate of maternal mortality in Indonesia prompted the government to reoptimize the Family Planning. There are several factors that influence a person's behavior, two of which are knowledge and attitude. Factors to be observed in this study, which aims to determine the relationship of mother's level of knowledge and attitude towards the behavior of the use of contraception in the health center district of Siko in 2013. Design research is a descriptive crosssectional study with a sample size of 49 people with accidential sampling. The analysis used in this research is using chi square analysis (X2). Instrumen in this study was a questionnaire that includes the data of respondents, questionnaires knowledge, attitudes, and behaviors. The results were obtained an average of 12.18 knowledge, median 12.00 , with a standard deviation of 2.369. Respondents who have a good knowledge of as much as $16 \%$, just $61 \%$, less than $22 \%$. Knowledge is lowest at the highest 817 . While the average maternal attitude is 8.33 , median 9.0 with a standard deviation 1.329 . The number of respondents who have a negative attitude is $49 \%$ and that $51 \%$ have a positive attitude. The minimum value of 5 attitudes and values maksmimum attitude is 11 . To obtain the behavior of the average value of 0.73 , the median standard deviation of 1.00 and 0.446 . The number of respondents who behave using birth control as much as $73.5 \%$ and were not as much as $26.5 \%$. Based on the results obtained by statistical tests where X2 (3.560) is smaller than X2 table (11.07). This shows a lack of correlation between knowledge and attitude toward the behavior, in other words, a high level of knowledge and a positive attitude does not mean behaviour be positive. From the results of this study are expected to examine other factors that relate more to the behavior that family planning programs launched by the government can be optimized, effective and efficient.
\end{abstract}

Key words : Maternal Mortality, Knowledge, Attitude.

\section{PENDAHULUAN}

Dikawasan ASEAN, angka kematian ibu saat melahirkan tertinggi adalah di Indonesia. Walaupun sudah terjadi penurunan dari 307/100 ribu kelahiran hidup (SDKI 200203) menjadi 263/100 ribu kelahiran hidup (BPS 2008), yang mana angka tersebut masih jauh tinggi diatas negara tetangga ASEAN lainnya, seperti Thailand 129/100 ribu, Malaysia 39/100 ribu dan Singapura 6/100 ribu. Tingginya angka kematian ibu ini tidak terlepas dari masih tingginya angka kehamilan yang tidak diinginkan yaitu mencapai 16,8 persen yang juga berkaitan dengan tingginya aborsi. Aborsi itu sendiri memberikan sumbangan terhadap kematian ibu sampai 13 persen. Disisi lain masih banyak ditemukan kehamilan yang tidak ideal (terlalu banyak, terlalu muda, terlalu tua, dan terlalu dekat jarak kehamilan), yang sangat membahayakan bagi kesehatan ibu atau lebih di kenal dengan " $4 \mathrm{~T}^{\text {ee }}$ (BKKBN:2009).

Dari berbagai permasalahan tersebut diatas jelaslah bahwa kematian ibu itu disebabkan oleh banyak faktor, tidak hanya disebabkan oleh faktor kesehatan semata.
Masih banyak faktor lain yang menjadi pengikut seperti sosial, budaya, ekonomi termasuk gender dan Keluarga Berencana. Dengan demikian program KB mempunyai pengaruh positif dalam mempercepat penurunan angka kematian ibu (AKI) dan penurunan angka kematian Bayi (AKB). Partisipan Program KB tidak hanya ditujukan kepada kaum istri semata, melainkan juga sebaiknya juga terdapat partisipasi aktif dari suami.

Peningkatan dan perluasan pelayanan keluarga berencana juga merupakan salah satu usaha untuk menurunkan angka kesakitan dan kematian ibu yang sedemikian tinggi akibat kehamilan yang dialami oleh wanita. Banyak wanita harus menentukan pilihan kontrasepsi yang sulit, tidak hanya karena terbatasnya jumlah metode yang tersedia tetapi juga karena metode-metode tertentu mungkin tidak dapat diterima sehubungan dengan kebijakan nasional KB, kesehatan individual dan seksualitas wanita atau biaya untuk memperoleh kontrasepsi4 (Depkes RI, 2008).

Sekarang ini program Keluarga Berencana Nasional mempunyai paradigma baru dengan visi yang telah diubah yaitu dari 
"Mewujudkan Norma Keluarga Kecil Bahagia dan Sejahtera (NKKBS)" menjadi "Mewujudkan Keluarga Berkualitas Tahun 2015" (catatan: NKKBS adalah konsep yang pernah dipakai pemerintah Orde Baru dalam kampanye Keluarga Berencana). Namun begitu keberhasilan suatu program tentulah dipengaruhi oleh banyak faktor, diantaranya dipengaruhi oleh tingkat pengetahuan terhadap program tersebut, dimana untuk mempunyai sikap yang positif tentang $\mathrm{KB}$ diperlukan pengetahuan yang baik, demikian sebaliknya bila pengetahuan kurang maka dorongan untuk mengikuti dan kepatuhan dalam menjalani program KB berkurang (Notoatmodjo, 2003).

Secara teori memang perubahan perilaku atau mengadopsi perilaku baru itu mengikuti tahap - tahap, yakni melalui proses perubahan: pengetahuan (knowledge), sikap (attitude), praktik (practice) atau disingkat "K-A-P". Beberapa penelitian telah membuktikan hal itu, namun penelitian lainnya juga membuktikan bahwa proses tersebut tidak selalu seperti teori diatas (K-A-P), bahkan di dalam praktik sehari-hari terjadi sebaliknya. Artinya, dimana seseorang telah berperilaku positif, meskipun pengetahuan dan sikapnya masih negatif (Notoatmodjo, 2003).

Bila dilihat dengan fenomena tersebut perlu diketahui adanya hubungan tingkat pengetahuan dan sikap ibu terhadap perilaku penggunaan kontrasepsi KB.

\section{METODE PENELITIAN}

Jenis penelitian ini adalah penelitian deskriptif korelasional dengan pendekatan cross sectional, yaitu baik variable dependen maupun independen diamati pada saat yang sama. Pemilihan desain dan rancangan penelitian ini untuk dapat mencari faktorfaktor yang berhubungan dengan pengetahuan dan sikap ibu terhadap perilaku penggunaan kontrasepsi KB di Siko Kecamatan Ternate Utara. Penelitian ini dilaksanakan di wilayah kerja Dinas Kesehatan Kota Ternate yaitu pada Puskesmas Siko.

Besar sampel pada penelitian ini adalah 49 ibu. Instrument yang digunakan adalah menggunakan kuesioner yang dirancang sedemikian rupa agar dapat dimengerti dan diisi sendiri oleh responden (Self Administered Questionnary).Analisa data dilakukan secara bertahap yaitu analisis univariat dan bivariat dengan chi square.

\section{HASIL}

Hasil penelitian menunjukan data tingkat pengetahuan ibu yang menggunakan kontrasepsi KB terbanyak berada pada tingkat pengetahuan cukup yaitu $41 \%$, berpengetahuan kurang sebesar $20 \%$ dan berpengetahuan baik sebesar $12 \%$.

Berdasarkan pengetahuan ada tiga kategori yaitu, baik, cukup dan kurang. Hasilnya adalah didapatkan sebanyak 20 orang yang berpartisipasi dalam ber $\mathrm{KB}$ tergolong dalam kategori berpengetahuan cukup , berpengetahuan kurang sebanyak 10 orang dan berpengetahuan baik 6 orang. Sedangkan hasil yang didapatkan untuk ibu yang tidak berpartisipasi dalam ber KB yaitu sebanyak 10 orang yang berpengetahuan cukup, 2 orang berpengetahuan baik dan 1 orang berpengetahuan kurang.

Table 1. Hasil Analisis Bivariat variabel Pengetahuan dengan Partisipasi Program KB di Puskesmas Siko Kecamatan Ternate Utara Tahun 2013

\begin{tabular}{rccc}
\multicolumn{1}{r}{ Variable } & \multicolumn{2}{c}{ Perilaku KB } & \multirow{2}{*}{ Total } \\
\cline { 2 - 3 } & Ya & Tidak & \\
\hline Pengetahuan & & & \\
$-\quad$ Baik & 6 & 2 & 8 \\
$-\quad$ Cukup & 20 & 10 & 30 \\
$-\quad$ Kurang & 10 & 1 & 11 \\
\hline \multicolumn{1}{r}{ Total } & 36 & 13 & 49 \\
\hline
\end{tabular}

Berdasarkan tabel.2 diatas diketahui bahwa variable berdasarkan sikap ada dua kategori yaitu positif dan negative. Hasilnya adalah didapatkan sebanyak 17 orang yang berpartisipasi dalam ber $\mathrm{KB}$ tergolong bersikap negative, dan 16 orang yang bersikap positif. Sedangkan hasil yang didapkan untuk ibu yang tidak berpartisipasi dalam ber $\mathrm{KB}$ yaitu sebanyak 7 orang bersikap negative dan 6 orang bersikap positif. 
Table 2. Hasil Analisis Bivariat Variabel Sikap dengan Partisipasi Program KB di Puskesmas Siko Kecamatan Ternate Utara Tahun 2013

\begin{tabular}{ccccc}
\hline & \multicolumn{1}{c}{ Variable } & \multicolumn{2}{c}{ Perilaku KB } & Total \\
\cline { 3 - 4 } & & Ya & Tidak & \\
\hline Sikap & & & & \\
- & Positif & 16 & 6 & 22 \\
- & Negatif & 17 & 7 & 24 \\
\hline \multicolumn{2}{r}{ Total } & 33 & 13 & 46 \\
\hline
\end{tabular}

\section{PEMBAHASAN}

Pada pembahasan ini peneliti akan menguraikan antara lain bagaimana pengetahuan ibu tentang kontrasepsi KB, sikap ibu tentang kontrasepsi $\mathrm{KB}$, perilaku ibu terhadap penggunaan kontrasepsi $\mathrm{KB}$, serta hubungan antara pengetahuan dan sikap terhadap perilaku penggunaan kontrasepsi $\mathrm{KB}$ di Puskesmas Siko Kecamatan Ternate Utara Tahun 2013.

Dari hasil perhitungan statistik distribusi frekuensi tingkat pengetahuan ibu mengenai kontrasepsi KB bahwa di Puskesmas Siko Kecamatan Ternate Utara Tahun 2013, sebagian besar ibu memiliki pengetahuan yang "cukup" mengenai kontrasepsi KB yaitu sebanyak 30 orang (61\%). Terbanyak kedua adalah yang memiliki pengetahuan yang "kurang" mengenai kontrasepsi KB yaitu sebanyak 11 orang (22\%), Jumlah yang paling sedikit adalah ibu-ibu yang memiliki pengetahuan yang "baik" mengenai kontrasepsi KB yaitu sebanyak 8 orang (16\%).

Menurut Green (dalam Notoatmodjo, 2003) mengatakan, peningkatan pengetahuan mempunyai hubungan positif dengan perubahan variabel perilaku. Pengetahuan dapat diperoleh dari peningkatan pendidikan, karena makin tinggi pendidikan seseorang makin realitis cara berpikirnya serta makin luas ruang lingkup jangkauan berpikirnya. Notoatmodjo (2003) mendefinisikan pengetahuan merupakan hasil dari tahu, dan ini terjadi setelah seseorang melakukan penginderaan terhadap suatu objek tertentu. Penginderaan terjadi melalui pancaindera manusia, yakni indera penglihatan, pendengaran, penciuman, perasaan, dan perabaan. Bila kita lihat berdasarkan pada teori Green (Notoatmojo, 2003) bahwa tingkat pengetahuan mempunyai hubungan positif dengan perubahan perilaku, maka tentu diharapkan sebagian besar (77\%) ibu akan memiliki perilaku yang sejalan dengan pengetahuannya yaitu akan memiliki perilaku berpartisipasi dalam kontrasepsi KB.

Dari perhitungan statistik pula didapat bahwa di Puseksmas Siko Tahun 2013, jumlah ibu yang memiliki sikap positif dan sikap negatif cenderung seimbang hanya berbeda 1 orang $(2 \%)$. Sebanyak 25 orang (51\%) memiliki sikap positif terhadap kontrasepsi KB. Sebanyak 24 orang (49\%) memiliki sikap negatif terhadap kontrasepsi KB.

Sikap merupakan reaksi atau respon yang masih tertutup dari seseorang terhadap suatu stimulus atau objek. Manifestasi sikap tidak dapat dilihat langsung tetapi hanya dapat ditafsirkan terlebih dahulu dari perilaku yang tertutup. Sikap secara nyata menunjukkan konotasi adanya kesesuaian reaksi terhadap stimulus tertentu yang dalam kehidupan seharihari merupakan reaksi yang bersifat emosional terhadap stimulus sosial 36 (Notoatmodjo, 2003).

Berdasarkan pada hasil statistik dan teori peneliti memiliki asumsi bahwa antara ibu yang memiliki sikap positif dan ibu yang memiliki sikap negatif terhadap kontrasepsi KB hanya berbeda tipis (2\%). Meskipun begitu kita tidak mengetahui berada pada tahap manakah sikap positif yang dimiliki ibu yang bersangkutan, apakah dalam tahap menerima, merespon, menghargai atau bertanggung jawab. Menurut Notoatmodjo (2003)38, meskipun seseorang memiliki sikap negatif, namun dia masih memungkinkan untuk menerima dan merespon suatu peristiwa atau kegiatan. Sehingga tidak menutup kemungkinan ibu yang memiliki sikap negatif terhadap kontrasepsi $\mathrm{KB}$ mampu menerima dan merespon perilaku penggunaan kontrasepsi KB.

Dari perhitungan statistik distribusi frekuensi perilaku ibu mengenai penggunaan kontrasepsi KB, didapat bahwa di Puskesmas Siko Kecamatan Ternate Utara Tahun 2013, sebagian besar ibu memiliki perilaku berpartisipasi dalam penggunaan kontrasepsi KB yaitu sebanyak 36 orang $(73,6 \%)$. Sementara yang tidak atau belum berpartisipasi 
dalam penggunaan kontrasepsi $\mathrm{KB}$ adalah sebanyak 13 orang $(26,5 \%)$.

Perilaku mencakup 3 domain, yakni: pengetahuan (knowledge), sikap (attitude) dan tindakan atau praktik (practice) (Notoatmodjo, 2003). Oleh sebab itu, mengukur perilaku dan perubahannya khususnya perilaku kesehatan juga mengacu kepada 3 domain tersebut. Disimpulkan bahwa perilaku seseorang atau masyarakat tentang kesehatan ditentukan oleh pengetahuan, sikap, kepercayaan, tradisi, dan sebagainya dari orang atau masyarakat yang bersangkutan. Di samping itu, ketersediaan fasilitas, sikap, dan perilaku para petugas kesehatan juga akan mendukung dan memperkuat terbentuknya perilaku.

Seorang ibu yang tidak mau mengikuti program kontrasepsi KB dapat disebabkan karena orang tersebut tidak atau belum mengetahui manfaat dari program tersebut (predisposing factors). Tetapi barangkali juga karena rumahnya jauh dari puskesmas atau peralatan yang tidak lengkap (enabling factors). Sebab lain mungkin karena para petugas kesehatan atau tokoh masyarakat lain disekitarnya tidak pernah memberikan contoh/penyuluhan tentang pentingya mengikuti program kontrasepsi KB (reinforcing factors).

Dari perhitungan statistik chi square untuk melihat hubungan antara pengetahuan (X1) dengan perilaku penggunaan kontrasepsi KB (Y) didapat nilai chi square hitung yang lebih kecil dari chi square tabel menunjukkan tidak adanya hubungan antara pengetahuan dengan perilaku partisipasi program KB.

Bila kita lihat dari hasil perhitungan statistik yang mana tidak ada hubungan antara pengetahuan dan perilaku penggunaan kontrasepsi KB, Dari perhitungan statitsik juga dapat diketahui bahwa tidak adanya hubungan antara sikap dengan perilaku partisipasi program KB. Sikap merupakan reaksi atau respon yang masih tertutup dari seseorang terhadap suatu stimulus atau objek. Manifestasi sikap tidak dapat dilihat langsung tetapi hanya dapat ditafsirkan terlebih dahulu dari perilaku yang tertutup. Sikap secara nyata menunjukkan konotasi adanya kesesuaian reaksi terhadap stimulus tertentu yang dalam kehidupan seharihari merupakan reaksi yang bersifat emosional terhadap stimulus social (Notoatmodjo, 2003). Namun begitu, tidak selalu individu yang memiliki sikap positif akan memiliki perilaku positif, begitu pula sebaliknya tidak selalu individu yang memiliki sikap negatif akan memiliki perilaku negatif, salah satu yang menjelaskan hal ini adalah karena adanya tingkatan sikap yang dijelaskan oleh (Notoatmodjo, 2003).

Dari hasil perhitungan statistik dengan menggunakan chi square, untuk melihat hubungan antara pengetahuan (X1) dan sikap (X2) terhadap perilaku penggunaan kontrasepsi KB (Y) didapat nilai chi square hitung lebih rendah dari chi square tabel, menunjukkan tidak adanya hubungan antara pengetahuan dan sikap dengan perilaku penggunaan kontrasepsi KB di Puskesmas Siko Kecamatan Ternate Utara. Tidak adanya hubungan dari perhitungan tersebut menunjukkan bahwa kita tidak bisa melakukan analisa lebih lanjut untuk melihat keeratan hubungan antara variablevariabel tersebut.

Teori Lawrence Green dan Notoatmodjo diatas menunjukkan bahwa ada banyak faktor yang mempengaruhi perilaku penggunaan kontrasepsi KB. Pengetahuan dan sikap dinyatakan hanya sebagai salah satu faktor yang cukup mempengaruhi perilaku seseorang. Namun begitu tentu diluar kedua faktor tersebut, tentu ada faktor-faktor lain yang mempengaruhi perilaku, baik dari faktor predisposisi, faktor pemungkin, maupun faktor penguat.

Bila kita perhatikan dari hasil penelitian yang peneliti lakukan di Puskesmas Siko, terlihat bahwa ternyata faktor pengetahuan akan kontrasepsi KB maupun faktor sikap terhadap kontrasepsi KB bukanlah merupakan salah satu faktor yang memiliki hubungan yang erat dengan perilaku penggunaan kontrasepsi $\mathrm{KB}$.

Begitupun kedua faktor tersebut (pengetahuan dan sikap) tidak bisa digunakan untuk memprediksi dan mengestimasi perilaku penggunaan kontrasepsi mengestimasi perilaku penggunaan kontrasepsi $\mathrm{KB}$, dengan kata lain kita tidak bisa memprediksi seseorang memiliki perilaku penggunaan kontrasepsi $\mathrm{KB}$ atau tidak hanya dari tingkat pengetahuan yang bersangkutan akan kontrasepsi maupun dari sikap yang bersangkutan akan kontrasepsi KB.

\section{KESIMPULAN DAN SARAN}

\section{Kesimpulan}

Berdasarkan hasil penelitian dan pembahasan hubungan tingkat pengetahuan dan sikap ibu terhadap perilaku penggunaan kontrasepsi KB di Puskesmas Siko Kecamatan Ternate Utara Tahun 2013, dapat disimpulkan bahwa di Puskesmas Siko Kecamatan Ternate Utara Tahun 2013, sebagian besar ibu 
memiliki pengetahuan yang cukup, sedangkan yang tidak berpatisipasi sebagian besar memiliki pengetahuan yang cukup. Sedangkan pada sikap ibu yang menjadi akseptor KB dan tidak memiliki hasil yang cenderung seimbang. Tidak adanya hubungan antara pengetahuan dan sikap dengan perilaku penggunaan kontrasepsi KB menunjukkan bahwa pengetahuan dan sikap akan kontrasepsi $\mathrm{KB}$ tidak bisa digunakan untuk memprediksi dan mengestimasi perilaku penggunaan kontrasepsi KB. Dengan kata lain, perilaku penggunaan kontrasepsi $\mathrm{KB}$ tidak dapat di tentukan oleh tingginya tingkat pengetahuan ibu akan kontrasepsi KB maupun oleh sikap ibu akan kontrasepsi KB.

\section{Saran}

Meningkatkan kegiatan sosialisasi mengenai $\mathrm{KB}$ sehingga menjangkau seluruh lapisan masyarakat, agar program KB dapat berjalan dengan optimal.

\section{DAFTAR PUSTAKA}

Algifari.2000. Analisis Regresi. Yogyakarta: BPFE

Anderson L.W \& Krathwol D.R. 2001. Atoxonomi for learning, teaching and assessing. New York :Longman.

Arikunto, S. 2002. Prosedur penelitian suatu pendekatan praktis. Jakarta : PT. Rineka Cipta.

BKKBN. 2000. Pedoman Penggarapan dan Peningkatan Partisipasi Pria dalam Program KB dan Kesehatan Reproduksi yang Berwawasan Gender. Jakarta.

BKKBN. 2003. Keluarga Berencana, Kesehatan Reproduksi,Gender,dan Pembangunan Kependudukan. Jakarta: BKKBN.

BKKBN. 2004. Strategi Peningkatan Program dan Kesehatan Reproduksi. Jakarta: BKKBN

BKKBN. 2005. Pengelolaan Program Keluarga Berencana di Kecamatan dan Desa.Jakarta.

BKKBN. 2006. Partisipasi pria dalam KB dan Kesehatan Reproduksi. Jakarta.

BKKBN. 2009. Seminar Contraceptive Update.UGM.Yogyakarta.

BPS (Badan Pusat Statistik) Jawa Barat 2008.

Cunningham F, Leveno K, Bloom S, Hauth J, Gilstrap L, Wenstrom K. Williams
Obstetric. 22nd ed. United States: The McGraw-Hill Companies; 2007.

Depdiknas.2005. Kamus Besar Bahasa Indonesia.Edisi III, Jakarta: Balai Pustaka.

Gema Pria BKKBN (2006)

Hartanto H. 1996. Keluarga Berencana dan Kontrasepsi. Jakarta: Sinar Harapan.

Hartanto H. 2004. Keluarga Berencana dan Kontrasepsi. Jakarta: Pustaka Sinar Harapan. 
